\title{
The impact of hyperbaric oxygen therapy on serological values of vascular endothelial growth factor (VEGF) and basic fibroblast growth factor (bFGF)
}

Susanne Jung ${ }^{1}$, Kai Wermker ${ }^{1}$, Harald Poetschik², Thomas Ziebura ${ }^{3}$, Johannes Kleinheinz ${ }^{1 *}$

\begin{abstract}
Background: Hyperbaric oxygen ( $\mathrm{HBO}$ ) therapy is an effective adjunct treatment for ischemic disorders such as chronic infection or chronic wounds. It combines hyperoxic effects with the stimulating potential of posttherapeutic reactive hypoxia. As its crucial effects, stimulation of fibroblast growth, induction of collagen synthesis and the initiation of angiogenesis are discussed. Angiogenesis is a multistage process resulting in the growth of blood vessels. It includes degradation of extracellular matrix, proliferation and migration of different cell populations and finally formation of new vessel structures. This complex chain of procedures is orchestrated by different cytokines and growth factors. Crucial mediators of angiogenesis are basic fibroblast growth factor (bFGF) and vascular endothelial growth factor (VEGF); their in-vivo function is still not fully understood.

Methods: Forty-three patients suffering from sudden sensorineural hearing loss or tinnitus were treated with $\mathrm{HBO}$. The therapy included 10 sessions of 90 minutes each, one session a day. Serological levels of bFGF and VEGF were assessed by enzyme-linked immunosorbent assays performed according to the manufacturer's instructions on day 1, 2, 5 and 10 of HBO therapy and were compared to mean values of the control group, related to the patient's age and sex, and their development observed over the ten days of HBO.

Results: There was no sex- or age dependency of bFGF observed in the present study, whereas under HBO our results showed a significant mitigation of the bFGF concentration. In the present data, there was no connection between the VEGF concentration and the patients' ages. Women showed significantly higher levels of VEGF. There was no significant change of VEGF concentration or the VEGF/bFGF ratio during HBO. All scored results varied within the range of standard values as described in the current literature.
\end{abstract}

Conclusions: A significant effect of HBO on serum concentrations of bFGF and VEGF was not verified in the present study. Additional application of exogenous growth factors in conjunction with HBO was not obviously linked by a coherent cause-and-effect chain as far as wound healing is concerned.

\section{Background}

Therapeutic administration of $\mathrm{HBO}$ was first mentioned in 1873 when miners were treated for decompression sickness [1]. Today, hyperbaric oxygen therapy is an effective treatment modality in the management of a variety of disorders, such as severe anaemia, gas

\footnotetext{
* Correspondence: Johannes.Kleinheinz@ukmuenster.de

'Department of Cranio-Maxillofacial Surgery, Research Unit Vascular Biology of Oral Structures (VABOS), University Hospital Muenster, Waldeyerstrasse 30, D-48149 Muenster, Germany

Full list of author information is available at the end of the article
}

gangrene, arterial gas embolism, carbon monoxide poisoning, radiation injuries, necrotizing infections, refractory wounds and chronic osteomyelitis but also acute ischemic disorders like acute sensorineural hearing loss or ischemic stroke [2].

Hyperbaric oxygen therapy involves the intermittent inhalation of $100 \%$ oxygen in chambers pressurized between 1.5 and 3.0 atmosphere absolute (ATA). An ATA is defined as the atmospheric pressure at sea level and is equivalent to 101.3 kilopascals or about 14.7

\section{Biomed Central}

(c) 2010 Jung et al; licensee BioMed Central Ltd. This is an Open Access article distributed under the terms of the Creative Commons Attribution License (http://creativecommons.org/licenses/by/2.0), which permits unrestricted use, distribution, and reproduction in any medium, provided the original work is properly cited. 
pounds per square inch. Its immediate effect is to increase dissolved oxygen content to above physiologic levels according to Krogh Erlang mechanism [3]. The benefit of $\mathrm{HBO}$ is based on the premise that raising tissue oxygen levels will enhance wound healing ability. The ignition for healing processes and angiogenesis is the lack of oxygen, but a sufficient oxygen supply is the basis for all proliferation or healing activities.

The positive effects of hyperoxia basically are

- vasoconstriction of arterioles, reduction of oedema

- bactericidal impact on anaerobial microbes and toxin-deactivation

- mobilisation and activation of leucocytes and macrophages

- activation of fibroblasts' collagen release

- activation of osteoclasts and stimulation of osteogensis

- cover of raised oxygen requirement of the damaged tissue in spite of impaired blood supply via stimulation of angiogenesis $[4,5]$.

A final destination of all sorts of repair process is the re-establishment of a sufficient perfusion and oxygen supply. The present study focuses on the relevant mediators of angiogenesis which are vascular endothelial growth factor (VEGF) and basic growth factor (bFGF). In angiogenesis, a number of growth factors (for example Angiopoietin-1, Platelet derived growth factor, Hypoxia inducing factor- $1 \alpha$, EphrinB2, Nitric Oxygen Synthase) have been found to play significant roles; VEGF and bFGF are the most extensively investigated angiogenic factors to date $[6,7]$.

As a single polypeptide bFGF is produced by a variety of cell populations, mainly by activated macrophages and thrombocytes. It belongs to one of the 22 members of the FGF family and transmits its signals via tyrosine kinase receptors $[8,9]$. Due to its ability to stimulate the activity of fibroblasts, endothelial cells, smooth muscle cells and neurons, bFGF is involved in many physiological and pathophysiological processes like growth, wound and bone healing, cell differentiation and proliferation, but also tumour progression and metastasis $[10,11]$. The key ability of bFGF is to induce angiogenesis via stimulation of VEGF expression, the effectiveness of a combined application is therefore easily explained. It is mitogenic on fibroblasts and endothelial cells [12].

VEGF is homodimer glycoprotein, its family includes 6 related proteins; VEGF 165 is most common and biologically active [13]. It is released by many cell populations as fibroblasts, monocytes, macrophages or lymphocytes [14]. The corresponding receptors belong to the tyrosine kinase family. VEGF induces angiogenesis on different levels: it acts as mitogen especially on endothelial cells, raises the vessel permeability and dilatation by releasing
$\mathrm{NO}$ and has chemotactic impact on other growth promoting cell populations [15].

Under hypoxia an increase of VEGF mRNA could be shown, and in addition to that the RNA's half-life was extended. This effect is translated by the hypoxia sensitive transcription factor HIF-1. The instantaneous angiogenic effect of VEGF is the increase in vessel permeability and mitogenic stimulation of endothelial cells. According to its potential, VEGF is also involved in pathophysiological processes like tumour growth; mainly in hypoxic tumour regions raised VEGF levels could be scored $[16,17]$.

The idea of the present study was to characterize and to quantify the effect of $\mathrm{HBO}$ on the expression of the growth factors bFGF and VEGF and, hence, to explain the mechanism of its therapeutic use.

\section{Methods}

Between May and October 1999, specimens were obtained from 86 persons: 43 patients and 43 control subjects (Table 1). In the HBO group, 43 patients treated for acute hearing loss or tinnitus were enrolled. During 10 days, they received $\mathrm{HBO}$ for 90 minutes each day, the applied pressure was 1.55 bar.

Blood samples of $7.5 \mathrm{ml}$ of peripheral blood were taken on day 1, 2, 5 and 10 of HBO treatment, after examination and informed consent of the control persons using standard serum test tubes, respectively; samples were stored at $2-5^{\circ} \mathrm{C}$, centrifuged $(1000 / \mathrm{min})$ after a 60 -minute period of coagulation and stored at $-80^{\circ} \mathrm{C}$ until analysis.

VEGF concentrations were assessed by performing a solidphase VEGF Immunoassay (VEGF Quantikine, DVE00, R\&D Systems GmbH, Wiesbaden-Nordenstadt, Germany R\&D Systems). The ELISA was performed according to the manufacturer's protocol; its sensitivity was described as $<25 \mathrm{pg} /$ $\mathrm{ml}$. The concentration of VEGF was expressed as $\mathrm{pg} / \mathrm{ml}$. VEGF was quantified by using a standard curve made by human VEGF ranging from $62 \mathrm{pg} / \mathrm{ml}$ to $707 \mathrm{pg} / \mathrm{ml}$. The chromogenic reaction was read at $450 \mathrm{~nm}$.

The bFGF concentrations were assessed by performing a solid-phase bFGF Immunoassay (FGF basic Quantikine, HSFB50, R\&D Systems GmbH, Wiesbaden-Nordenstadt, Germany R\&D Systems). The ELISA was performed according to the manufacturer's protocol; its sensitivity was described as $<5 \mathrm{pg} / \mathrm{ml}$. The concentration of bFGF was expressed as $\mathrm{pg} / \mathrm{ml}$. The bFGF was quantified by using a standard curve made by human bFGF ranging from $0 \mathrm{pg} / \mathrm{ml}$ to $4.40 \mathrm{pg} / \mathrm{ml}$. The chromogenic reaction was read at $490 \mathrm{~nm}$.

\section{Evaluated parameters}

The evaluation focused on the most important angiogenic factors VEGF and bFGF and their serological values (Table 2) [18,19]. 
Table 1 Patient data

\begin{tabular}{|c|c|c|c|c|c|c|}
\hline & $\mathrm{n}$ & sex & age & average & SD & diagnosis \\
\hline HBO group & 43 & 22 ơ, 21 ㅇ & $16-62$ years & 43.3 years & 11.4 years & $\begin{array}{c}28 \text { acute hearing loss } \\
15 \text { tinnitus }\end{array}$ \\
\hline Control group & 43 & 19 on, 24 우 & $18-65$ years & 29.9 years & 14.1 years & - \\
\hline
\end{tabular}

Distribution of sex and age in the study and the control group (SD = standard deviation)

\section{Statistical analysis}

The results are expressed as mean values $+/$ - standard deviations (SD) for each group. Normal curve of distribution of results, means and SD were controlled with the David, Pearson and Stephens test. Data were statistically analyzed by using the analysis of variance (ANOVA) and Scheffe test. Differences between groups were assessed using the Whitney Mann U-test. An error probability of $\mathrm{p}<0.05$ was adopted as the statistically significant level.

\section{Results}

bFGF

There was no significant difference in bFGF concentration between $\mathrm{HBO}$ and control group before $\mathrm{HBO}$. There was no sex- or age dependency according to our results. In the present study, under $\mathrm{HBO}$ a significant mitigation of the bFGF concentration within standardvalues could be observed (Table 3). Differences between bFGF concentrations at day 1 and day 10 within the HBO group reached statistical significance $(\mathrm{p}=0.041)$.

\section{VEGF}

There was a significant difference in VEGF concentration between patients and control group before HBO ( $p$ $=0.015)$. In our results there was no connection between the VEGF concentration and the patients' ages. Women showed significantly higher levels of VEGF $(279.65+/-243.70 \mathrm{pg} / \mathrm{ml})$ compared to male subjects $(193.58+/-162.39 \mathrm{pg} / \mathrm{ml})(\mathrm{p}=0.026)$. There was no significant change of VEGF concentration under $\mathrm{HBO}$ (Table 4).

\section{VEGF/bFGF ratio}

Although a slight increase of the ratio could be documented, there was no significant variance of the VEGF/ bFGF ratio in the present study (Figure 1).

Table 2 Characteristics of bFGF and VEGF

\begin{tabular}{|c|c|c|c|c|c|}
\hline & gene & weight & receptor & synthesis & $\begin{array}{c}\text { standard value } \\
\mathrm{pg} / \mathrm{ml}\end{array}$ \\
\hline bFGF & $\begin{array}{l}5 p 12- \\
\text { p13 }\end{array}$ & 18 kDa & $\begin{array}{l}\text { tyrosine } \\
\text { kinase }\end{array}$ & macrophages & 2.45 \\
\hline VEGF & $\begin{array}{l}\text { 6p12- } \\
\text { p21 }\end{array}$ & $\begin{array}{l}39-45 \\
\mathrm{kDa}\end{array}$ & $\begin{array}{l}\text { tyrosine } \\
\text { kinase }\end{array}$ & fibroblasts & 224 \\
\hline
\end{tabular}

Characteristics of bFGF and VEGF

\section{Discussion}

Under HBO therapy a significant reduction of bFGF was detected. The concentration of VEGF did not change but was measured significantly higher in female test persons. All collected results were within the range of standard values according to the current literature.

The influence of the ischemic inner-ear disorder for which the HBO group was treated could not be fully excluded as an interfering factor. Yet it seemed highly implausible because so far only grave diseases have been reported to affect bFGF and VEGF concentration [20]. There are several explanations for the reduced bFGF level under $\mathrm{HBO}$. One hypothesis states that there are simply more bFGF molecules binding on their receptor and transmitting their signal. These molecules are no longer detectable for the performed assays.

There might be a higher rate of binding on circulation proteins in the course of repair processes: these ligandreceptor complexes are possibly the activating agents inducing fibroblast proliferation, collagen release, osteoand angioneogenesis.

Eventually, a therapy period of ten days was observed. Possibly, there was a delayed cellular adaptation to the HBO treatment, where protective cell populations have to be activated for repair mechanisms to oxygen freeradical damage. There are hints in literature that effective cellular responses to $\mathrm{HBO}$ cannot be expected before day seven of treatment [21].

Another consideration is that acute sensoneurinal hearing loss and tinnitus do not require the induction of wound healing algorithm to a comparable extend as tissue lesions or chronic infections do. So the restraint reaction of bFGF and VEGF in our data might be explained.

Table 3 Serological values of bFGF

\begin{tabular}{ccc}
\hline & \multicolumn{2}{c}{ bFGF in pg/ml } \\
& mean & SD \\
\hline Control group & 2.65 & 3.01 \\
HBO group - day 1 & 3.25 & 2.38 \\
day 2 & 2.80 & 1.94 \\
day 5 & 2.55 & 1.72 \\
day 10 & 2.12 & 1.23 \\
\hline
\end{tabular}

Serological values of bFGF in the study and the control group at definite times 
Table 4 Serological values of VEGF

\begin{tabular}{ccc}
\hline & \multicolumn{2}{c}{ VEGF in pg/ml } \\
& mean & SD \\
\hline Control group & 190.63 & 175.27 \\
HBO group - day 1 & 282.60 & 252.87 \\
day 2 & 290.16 & 248.35 \\
day 5 & 269.89 & 224.18 \\
day 10 & 279.58 & 263.24 \\
\hline
\end{tabular}

Serological values of VEGF in the study and the control group at definite times

The observed higher levels of VEGF in females find their explication in their cycle-dependent hormone regulation.

As far as VEGF concentration during $\mathrm{HBO}$ is concerned our data suggests that the reactive hypoxia was not enough of a stimulus for increased VEGF release. Yet in-vivo and in-vitro studies have underlined the fact that hypoxia is a potent stimulus for VEGF release [22]. In malignantly transformed tissues the highest rates of VEGF were found in hypoxic, necrotic areas [23].

Application of recombinant human VEGF showed promising results in animal studies by promoting collateral formation in occluded vessels or proliferation of endothelial cells in severed arteries [24].

A not yet mentioned field of interest dealing with VEGF lies in tumour diagnosis and follow-up care. VEGF might be able to act as an indicator of tumour neo angiogenesis for elevated VEGF levels are observed and even correlate with the tumour mass in patients with malignant melanoma [25].

Some tumour entities as sarcomas are not accompanied by elevated tumour markers like PSA in prostate cancer [26,27]. As soon as VEGF's role in tumour growth, in metastasis and, in particular, tumour neoangiogenesis will be further elucidated, VEGF serum

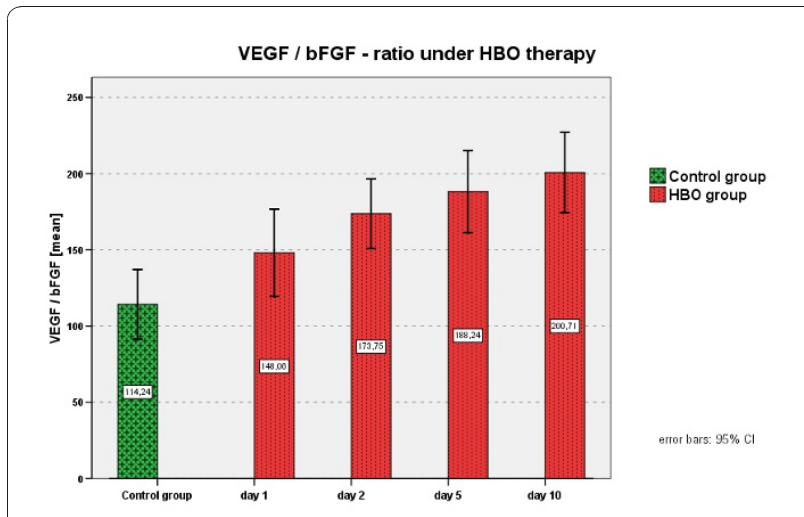

Figure 1 VEGF/bFGF ratio under $\mathrm{HBO}$ level and its development during the etiopathology might become valuable prognostic tools [28,29].

\section{Conclusions}

Although in the present data a significant effect of $\mathrm{HBO}$ on serum concentrations of bFGF and VEGF was not verified, many studies revealed that intermittent $\mathrm{HBO}$ exposure plays a direct role in vascular growth; the biochemical processes, however, have not been fully understood. Additional application of exogenous growth factors in conjunction with $\mathrm{HBO}$ was not obviously linked by a coherent causeand-effect chain as far as wound healing is concerned.

\section{Author details}

'Department of Cranio-Maxillofacial Surgery, Research Unit Vascular Biology of Oral Structures (VABOS), University Hospital Muenster, Waldeyerstrasse 30, D-48149 Muenster, Germany. ${ }^{2}$ Private practice, Lueneburg, Germany.

${ }^{3}$ Department of Orthodontics, University Hospital Muenster, Germany.

\section{Authors' contributions}

SJ carried out the immunoassays and drafted the manuscript, KW and SJ participated in the design of the study and performed the statistical analysis. $\mathrm{HP}$ and JK conceived of the study, and participated in its design and coordination and helped to draft the manuscript. HP and TZ were involved in revising the article and all authors read and approved the final manuscript.

\section{Competing interests}

The authors declare that they have no competing interests.

Received: 1 June 2010 Accepted: 22 December 2010

Published: 22 December 2010

\section{References}

1. Jacobson $\mathrm{JH}$, Morsch $\mathrm{JCH}$, Rendell-Baker L: The historical perspective of hyperbaric therapy. Ann N Y Acad Sci 1965, 117:651-670.

2. Camporesi RM: Hyperbaric oxygen therapy: A Committee Report. Undersea and Hyperbaric Medical Society Kensington MD USA; 1996.

3. Kindwall EP, Whelan HT: Hyperbaric medicine practice Flagstaff: Best Publishing Company; 2008.

4. Hunt TK, Pai MP: The effect of varying ambient oxygen tensions on wound metabolism and collagen synthesis. Surg Gynecol Obstet 1979, 135:561-7.

5. Siddiqui A, Galiano RD, Connors D, Gruskin E, Wu L, Mustoe TA: Differential effects of oxygen on human dermal fibroblasts: acute versus chronic hypoxia. Wound Repair Regen 1996, 4:211-8.

6. Ferrara N, Davis-Smyth T: The biology of vascular endothelial growth factor. Endocrine Rev 1997, 18:4-25.

7. Inui K, Maeda M, Sano A, Fujioka K, Yutani Y, Sakawa A, Yamano Y, Kato Y, Koike T: Local application of basic fibroblast growth factor minipellet induces the healing of segmental bony defects in rabbits. Calcif Tissue Int 1998, 63:490-5.

8. Folkman J, Klagsbrun M, Sasse J, Wadzinski M, Ingber D, Vlodavsky I: A heparin-binding angiogenic protein-basic fibroblast growth factor-is stored within basement membrane. Am J Pathol 1988, 130:393-400.

9. Robson $M C$, Phillips $L G$, Lawrence WT, Bishop JB, Youngerman JS, Hayward PG, Broemeling LD, Heggers JP: The safety and effect of topically applied recombinant basic fibroblast growth factor on the healing of chronic pressure sores. Ann Surg 1992, 216:401-6.

10. Brattström D, Bergqvist M, Larsson A, Holmertz J, Hesselius P, Rosenberg L, Brodin O, Wagenius G: Basic fibroblast growth factor and vascular endothelial growth factor in sera from non-small cell lung cancer patients. Anticancer Res 1998, 18:1123-7.

11. Dellacono FR, Spiro J, Eisma R, Kreutzer D: Expression of basic fibroblast growth factor and its receptors by head and neck squamous carcinoma tumor and vascular endothelial cells. Am J Surg 1997, 174:540-4. 
12. Hayward P, Hokanson J, Heggers J, Fiddes J, Klingbeil C, Goeger M, Robson M: Fibroblast growth factor reserves the bacterial retardation of wound contraction. Am J Surg 1992, 163:288-93.

13. Mattei MG, Borg JP, Rosnet O, Marmé D, Birnbaum D: Assignment of vascular endothelial growth factor (VEGF) and placenta growth factor (PLGF) genes to human chromosome 6p12-p21 and 14q24-q31 regions, respectively. Genomics 1996, 32:168-9.

14. Drake CJ, Little CD: Exogenous vascular endothelial growth factor induces malformed and hyperfused vessels during embryonic neovascularization. Proc Natl Acad Sci USA 1995, 92:7657-61.

15. Keck PJ, Hauser SD, Krivi G, Sanzo K, Warren T, Feder J, Connolly DT: Vascular permeability factor, an endothelial cell mitogen related to PDGF. Science 1989, 246:1309-12.

16. Plate $\mathrm{KH}$, Breier $\mathrm{G}$, Risau W: Molecular mechanisms of developmental and tumor angiogenesis. Brain Pathol 1994, 4:207-18.

17. Senger DR, Van de Water L, Brown LF, Nagy JA, Yeo KT, Yeo TK, Berse B, Jackman RW, Dvorak AM, Dvorak HF: Vascular permeability factor (VPF, VEGF) in tumor biology. Cancer Metastasis Rev 1993, 12:303-24.

18. Fong GH, Rossant J, Gertsenstein M, Breitman ML: Role of the Flt-1 receptor tyrosine kinase in regulating the assembly of vascular endothelium. Nature 1995, 376:66-70.

19. Waltenberger J, Claesson-Welsh L, Siegbahn A, Shibuya M, Heldin CH: Different signal transduction properties of KDR and Flt1, two receptors for vascular endothelial growth factor. J Biol Chem 1994, 269:26988-95.

20. Dietz A, Rudat V, Vanselow B, Conradt C, Möhler T: [Predictive value of serum levels of basic fibroblast growth factor, vascular endothelial growth factor and matrix metalloproteinase-2 in advanced carcinomas of the head and neck]. HNO 1999, 47:695-701.

21. Kang TS, Gorti GK, Quan SY, Ho M, Koch RJ: Effect of hyperbaric oxygen on the growth factor profile of fibroblasts. Arch Facial Plast Surg 2004, 6:31-5.

22. Ladoux A, Frelin C: Hypoxia is a strong inducer of vascular endothelial growth factor mRNA expression in the heart. Biochem Biophys Res Commun 1993, 195:1005-10.

23. Folkman J: Angiogenesis in cancer, vascular, rheumatoid and other disease. Nat Med 1995, 1:27-31.

24. Asahara T, Bauters C, Zheng LP, Takeshita S, Bunting S, Ferrara N, Symes JF, Isner JM: Synergistic effect of vascular endothelial growth factor and basic fibroblast growth factor on angiogenesis in vivo. Circulation 1995, 92:11365-71.

25. Salven P, Mänpää H, Orpana A, Alitalo K, Joensuu H: Serum vascular endothelial growth factor is often elevated in disseminated cancer. Clin Cancer Res 1997, 3:647-51.

26. Dirix LY, Vermeulen PB, Pawinski A, Prové A, Benoy I, De Pooter $C$, Martin $M$, Van Oosterom AT: Elevated levels of the angiogenic cytokines basic fibroblast growth factor and vascular endothelial growth factor in sera of cancer patients. Br J Cancer 1997, 76:238-43.

27. Kondo S, Asano M, Suzuki H: Significance of vascular endothelial growth factor/vascular permeability factor for solid tumor growth, and its inhibition by the antibody. Biochem Biophys Res Commun 1993, 194:1234-41.

28. Salven P, Heikkilä P, Anttonen A, Kajanti M, Joensuu H: Vascular endothelial growth factor in squamous cell head and neck carcinoma: expression and prognostic significance. Mod Pathol 1997, , 10: 1128-33.

29. Weidner N, Semple JP, Welch WR, Folkman J: Tumor angiogenesis and metastasis-correlation in invasive breast carcinoma. N Engl J Med 1991, 324:1-8.

doi:10.1186/1746-160X-6-29

Cite this article as: Jung et al:: The impact of hyperbaric oxygen therapy on serological values of vascular endothelial growth factor (VEGF) and basic fibroblast growth factor (bFGF). Head \& Face Medicine 2010 6:29.

\section{Submit your next manuscript to BioMed Central and take full advantage of:}

- Convenient online submission

- Thorough peer review

- No space constraints or color figure charges

- Immediate publication on acceptance

- Inclusion in PubMed, CAS, Scopus and Google Scholar

- Research which is freely available for redistribution

Submit your manuscript at www.biomedcentral.com/submit
Biomed Central 